\title{
Capturing foraging and resting behavior using nested multivariate Markov models in an air-breathing marine vertebrate
}

\author{
Ben G. Weinstein ${ }^{1 *}$ (D), Ladd Irvine ${ }^{1}$ and Ari S. Friedlaender ${ }^{1,2}$
}

\begin{abstract}
Background: Matching animal movement with the behaviors that shape life history requires a rigorous connection between the observed patterns of space use and inferred behavioral states. As animal-borne dataloggers capture a greater diversity and frequency of three dimensional movements, we can increase the complexity of movement models describing animal behavior. One challenge in combining data streams is the different spatial and temporal frequency of observations. Nested movement models provide a flexible framework for gleaning data from longduration, but temporally sparse, data sources.

Results: Using a two-layer nested model, we combined geographic and vertical movement to infer traveling, foraging and resting behaviors of Humpback whales off the West Antarctic Peninsula. This approach refined previous work using only geographic data to delineate coarser behavioral states. Our results showed increased intensity in foraging activity in late season animals as the whales prepared to migrate north to tropical calving grounds. Our model also suggests strong diel variation in movement states, likely linked to daily changes in prey distribution.
\end{abstract}

Conclusions: Using a combination of two-dimensional and three-dimensional movement data, we highlight the connection between whale movement and krill availability, as well as the complex spatial pattern of whale foraging in productive polar waters.

Keywords: Humpback whales, West Antarctic peninsula, Landscape ecology, Movement model, Hidden-markov models, Antarctic krill, Dive behavior

\section{Background}

Animal movement provides insight into the ecology, life history and conservation needs of mobile species. An ongoing challenge in movement ecology is associating the spatial patterns of movement with the underlying behaviors such as foraging, predation, and reproduction [1-3]. Strengthening the connection between behavior and spatial patterns of movement requires additional mechanistic data beyond two dimensional representations of animal activity [4]. For marine animals, time-at-depth recorders are an important tool for creating more realistic models of foraging behaviors [5]. Yet incorporating such data with derived movement tracks is complicated by potential mismatches in the temporal

\footnotetext{
* Correspondence: ben.weinstein@weecology.org

'Department of Fisheries and Wildlife, Marine Mammal Institute, Oregon State University, 2030 Marine Science Drive, Newport, OR 97365, USA Full list of author information is available at the end of the article
}

frequency of data collection, as well as the ecological scale at which behaviors occur [2].

To create a more accurate depiction of behavior, analyses can move towards multi-layer models of nested behaviors [6]. Multi-layer models provide two advantages. First, datasets collected at different temporal and spatial scales can be analyzed jointly, without needing to downsample data to a common observation frequency. For example, satellite-based geographic observations are often collected at relatively long intervals, compared to biometric [5] or accelerometer data [7]. Secondly, nested models allow greater partitioning among behavioral states. While many studies divide behavior into broad discrete states, we are often interested in finer behavioral categories that describe animal life history [8]. Rather than creating additional single-layer states, nested states allow us to first model the predictors of broad categories, such as foraging

(c) The Author(s). 2018 Open Access This article is distributed under the terms of the Creative Commons Attribution 4.0 International License (http://creativecommons.org/licenses/by/4.0/), which permits unrestricted use, distribution, and 
versus traveling, then subdivide these states based on local conditions or timeframes [2].

We use a nested multivariate movement model to capture both the two-dimensional space use and the vertical foraging behavior in Antarctic Humpback whales (Megaptera novaeangliae). Antarctic Humpback whales are large filter feeding baleen whales commonly found in Antarctic waters during the austral summer. Humpbacks in these waters primarily feed on Antarctic krill (Euphausia superba), which form large aggregative swarms during the austral summer and fall $[9,10]$. At the broad scale, previous work has used two-dimensional visual observations to highlight areas of whale density [11-13], and satellite tag data to assess seasonal changes in movement [14]. Due to physiology and feeding mechanics, there is a minimal krill density at which foraging is energetically favorable for humpback whales, creating discrete bouts of feeding and traveling [15]. At broad scales, movement behaviors often last multiple days, as whales travel among and forage within productive patches of krill swarms [14]. However, single day tagging studies show a diversity of vertical behaviors related to foraging movements, with both resting and exploratory dives co-occurring with feeding dives within areas of high krill density [16]. Connecting these local patterns of dive intensity with regional patterns of movement is key in both delineating primary foraging habitat [17], as well as creating detailed physiological models of energetic demands [18].

Our aim is to create a broad-scale quantitative movement model that describes the spatial and temporal properties of dive behaviors, connects the high frequency observation of dives with the lower frequency of observation of geographic location, and realistically captures the time spent in foraging and resting behaviors at local scales. Weinstein and Friedlaender [14] divided movement into traveling and area-restricted search states, and showed an increase in the proportion of time in area-restricted search later in the austral fall. This could either come from 1) greater foraging intensity needed to fulfill energetic reserves before migration, 2) increased resting behavior to preserve energetic expenditure, or 3) reduced opportunity for traveling to new patches due to sea ice advance. By refining spatial patterns of movement with nested foraging behaviors, we can connect seasonal changes in behavior with potential changes in foraging intensity. The seasonal demands in energy expenditure may be critical in understanding the rebound in humpback populations from historic declines $[19,20]$, the effect of rapidly changing Antarctic marine environment [21, 22], and the potential competition with the Antarctic Krill fishery $[11,23]$.

\section{Methods}

\section{Satellite tagging and tracking}

We deployed 11 Wildlife Computers (Redmond, WA, USA) SPOT5 Platform Transmitting Terminals (PTTs) off the Western Antarctic Peninsula in 2016 (Table 1). Each tag is contained in a sterilized housing designed to penetrate the whale's skin and blubber up to $290 \mathrm{~mm}$, and is anchored in the tissue beneath the blubber with stainless steel barbs, with the transmitting antenna remaining free outside of the animal. All whales were presumed to be adults based on a minimum size of $12 \mathrm{~m}$. Tags were deployed from a range of 3-10 $\mathrm{m}$ and placed near the dorsal fin, which contains the thickest blubber layer, and provides the greatest height to transmit positional information via the exposed antenna.

Satellite transmissions were activated via a salt-water switch and received by the Argos satellite system which estimated the tag position based on the number and temporal distribution of transmissions received during a satellite pass. Tags sampled depth at $1 \mathrm{~Hz}$ using an onboard pressure sensor and we defined dives as submergence below $10 \mathrm{~m}$ for more than $20 \mathrm{~s}$. Dive data were aggregated and transmitted in packages containing information on dive duration, maximum dive depth, and dive shape (determined by percentage of time spent at $80 \%$ of the maximum dive depth). All tags were set without duty cycling and attempted to transmit data on each surfacing. We filtered raw observations to remove transmissions without location data, duplicate timestamps, locations on land, and implausible speed between consecutive locations $(20 \mathrm{~km} /$ hour $)$ to create a conservative set of observations. We then filtered our observations to preserve continuous movement tracks, with a maximum 12-h window between points and a minimum track length of $24 \mathrm{~h}$. Humpbacks engage in a northward migration from the West Antarctic Peninsula to western South America at the end of the austral fall. Migration events were identified as unidirectional movement north and removed from the analysis. The final dataset was

Table 1 Tag data for the 11 humpback whale tracks used in this study. The number of observed Argos locations and dive records are shown for each animal

\begin{tabular}{lllll}
\hline Animal & Argos & Dive & Start & End \\
\hline 131,111 & 173 & 375 & $3 / 23 / 161: 01$ & $3 / 27 / 1616: 25$ \\
131,115 & 179 & 850 & $2 / 26 / 1613: 20$ & $3 / 1 / 1613: 54$ \\
131,116 & 457 & 1475 & $2 / 26 / 1621: 28$ & $3 / 6 / 1614: 18$ \\
131,127 & 2495 & 6780 & $4 / 26 / 1614: 05$ & $7 / 13 / 1614: 01$ \\
131,128 & 52 & 60 & $4 / 26 / 1613: 25$ & $4 / 27 / 166: 36$ \\
131,130 & 151 & 1014 & $4 / 25 / 1617: 53$ & $4 / 29 / 1617: 30$ \\
131,132 & 589 & 1703 & $4 / 25 / 1620: 23$ & $5 / 10 / 1614: 11$ \\
131,133 & 2077 & 6419 & $4 / 26 / 1613: 24$ & $7 / 5 / 1616: 04$ \\
131,134 & 653 & 1445 & $4 / 26 / 160: 08$ & $5 / 12 / 1611: 31$ \\
131,136 & 1970 & 4874 & $4 / 26 / 1613: 25$ & $6 / 29 / 1618: 11$ \\
154,187 & 486 & 1380 & $3 / 21 / 1620: 05$ & $4 / 2 / 1616: 10$ \\
\hline
\end{tabular}


comprised of 11 individuals, with 9283 Argos observations, and 26,375 recorded dives.

\section{Movement modeling}

To associate spatial patterns of animal movement with predicted behavior phases, we begin with a hierarchical state-space model following $[14,24,25]$. This model allowed us to estimate multiple behavioral states, and account for measurement uncertainty using Markov Chain Monte Carlo (MCMC) simulation. As in previous work, we modeled whale movement as a function of the autocorrelation in step size and turning angles for two distinct behavioral phases: traveling and area-restricted search [24]. The traveling state is defined as large scale movements with high autocorrelation and small turning angles. Area-restricted search is defined as short step lengths with high turning angles.

\section{Process model}

$$
\begin{aligned}
& Y_{i, g, t+1} \sim \operatorname{Multivariate} \operatorname{Normal}\left(d_{i, g, t}, \sigma\right) \\
& d_{i, g, t}=Y_{i, g, t}+\gamma_{s_{i, g, t}}{ }^{*} T_{i, g, t}{ }^{*}\left(Y_{i, g, t}-Y_{i, g, t-1}\right) \\
& T_{i, g, t}=\left[\begin{array}{cc}
\cos \left(\theta_{s_{i g, t}}\right) & -\sin \left(\theta_{s_{i, g, t}}\right) \\
\sin \left(\theta_{s_{i, g, t}}\right) & \cos \left(\theta_{s_{i, g, t}}\right)
\end{array}\right] \\
& S_{i, g, t}^{\prime} \sim \operatorname{Multinomial}\left(\phi_{i, g, t}^{\prime} 1-\phi_{i, g, t}^{\prime}\right) \\
& \operatorname{logit}\left(\phi_{i, g, t}^{\prime}\right)=\alpha^{\prime}{ }_{s^{\prime} i, g, t, s_{i, g, t-1}}^{\prime}
\end{aligned}
$$

\section{Observation model}

$$
\begin{gathered}
w_{i, g, t, u} \sim \text { Multivariate Normal }\left(\hat{z}_{i, g, t, u}, \tau_{\text {argos }}\right) \\
\hat{z}_{i, g, t, u}=\left(1-j_{i, g, t, u}\right) * Y_{i, g, t-1}+j_{i, g, t, u}{ }^{*} Y_{i, g, t}
\end{gathered}
$$

This process model estimates the geographic location $(Y)$ of individual $(i)$ at time $(t)$ along a track $(g)$. This location is multivariate normally distributed with a mean location $(d)$ and a variance in location $(\sigma)$. The mean location is a first-order Markov process, such that it depends on the difference in location to the previous step $\left(Y_{i, g, t}-Y_{i}\right.$, $g, t-1)$, plus the movement at time $t$. This movement is a function of the degree of autocorrelation in step length $(\gamma)$ and turning angles $(\mathrm{T})$, with a mean turning angle $(\theta)$. Step lengths and turning angles are considered to come from two behavioral states, 'traveling' and 'area-restricted search'. The predicted behavioral state $\left(S^{\prime}\right)$ is a Bernoulli draw with a probability of being in the traveling state $\left(\phi^{\prime}{ }_{i}\right.$, $g, t)$ or in the area-restricted search state $\left(1-\phi^{\prime}{ }_{i, g, t}\right)$.The prime notation denotes the first layer of behavioral states. The transition probabilities $\left(\phi^{\prime}\right)$ among behavioral states $\left(\mathrm{S}^{\prime}\right)$ depends on the current behavioral state and the behavioral state of the previous observation. To infer the sequence of behaviors, the most likely state $\left(\phi_{i, g, t}^{\prime}>0.5\right)$ is used for each observation.

The observation model describes our ability to detect location given the Argos observations. We chose to model movement on a six-hour time step, which was a conservative balance between accounting for gaps in Argos transmissions on data, and ensuring that behaviors do not change between observations. Within a time-step, individuals are assumed to move in a straight line, such that each Argos observation is expressed as a proportion of the six-hour time interval $(j, g, t, u)$. The variance in the Argos observation $\left(\tau_{\text {argos }}\right)$ was fixed for each Argos error class following the results reported in Jonsen et al. (2005).

\section{Incorporating vertical movement}

From the base model above, we added a nested behavioral state that describes the latent process that generates dive depths. The model is hierarchical, observations are first defined in terms of their geographic movement, and then refined based on vertical movement. We divided the area-restricted search state into foraging and resting sub-states based on single day tagging studies which showed both behaviors occurring during foraging movements [16]. We chose not to further partition the traveling state, since our aim is to clarify the behaviors associated with the area-restricted search state. The behavioral sub-state $\left(S^{\prime \prime}\right)$ is a separate Markov chain that generates observed dive depths a mixture of normally distributed dive distributions.

$$
\begin{aligned}
& S_{i, g, t, u}^{\prime \prime} \sim \operatorname{Multinomial}\left(\phi_{i, g, t, u}^{\prime \prime} \quad 1-\phi_{i, g, t, u}^{\prime \prime}\right) \\
& \operatorname{logit}\left(\phi_{i, g, t, u}^{\prime \prime}\right)=\alpha^{\prime \prime}{ }_{s_{i, g, t}^{\prime}, s_{i, g, t, u-1}^{\prime \prime}}^{\prime \prime} \\
& \operatorname{Dive}_{i, g, t, t, u} \sim \operatorname{Normal}\left(\mu_{S_{i, g, t, u}^{\prime \prime},}^{\prime \prime}, \sigma_{S_{i, g, t, u}^{\prime \prime}}^{\prime \prime}\right)
\end{aligned}
$$

Note that transition probability relates both to the sub-state of the previous dive ( $\left.\mathrm{S}^{\prime \prime}\right)$, as well as the behavioral state of the top layer $\left(S^{\prime}\right)$. We arrived at this model through extensive exploration of single layer models which could not balance the multivariate information of both 2-dimensional and 3-dimenisonal data without needing unrealistic prior bounds on the latent behavioral states.

Dive priors were sampled from a zero-truncated normal distribution since dive depths must be positive. The traveling state was given a broad dive prior with a mean dive depth between 0 and $30 \mathrm{~m}$. Animals are unlikely to dive deeper than $100 \mathrm{~m}$ during traveling phases, as deeper dives would decrease horizontal speed and increase physiological demand. Resting dives were similarly constrained to be a mean depth of 0 to $30 \mathrm{~m}$ [16]. Based on evaluation of the data and previous dive profiles, foraging dives were given a broad prior, with mean depth between $50 \mathrm{~m}$ and $250 \mathrm{~m}$ $[26,27]$. We believe these priors are biologically defensible, reasonably broad, and promote convergence during 
Bayesian simulation. Simulations were run in R (R Development Core Team 2015) and JAGS [28] with 2 MCMC chains running in parallel, each running for a total of 30,000 iterations. The first 28,000 iterations were discarded as burn-in. The final 2000 iterations were thinned by 4 to reduce autocorrelation and the computational burden of saving a large number of latent behavioral states to file. Chain convergence was assessed by comparing the within chain variances to the between chain variance using the Gelman-Rubin statistic. Parameters with Gelman-Rubin $(\hat{r})$ of less than 1.1 were considered converged following Gelman and Hill [29]. Source code and data visualizations are available on github (https://bw4sz.github.io/WhalePhys/).

\section{Results}

Our filtered data contained 8958 Argos observations (Fig. 1) and 21,417 dive records for 11 adult humpback whales. The average number of dives per individual was 1947 , with an average deployment duration of 26.71 days. The movement model converged in $13.5 \mathrm{~h}$ with Rhat statistics less than 1.1 for all parameters [29]. Movement parameter estimates can be found in Additional file 1: Table S1, and the estimated latent dive distributions for each behavior are shown in Fig. 2. The area-restricted search state showed strong temporal autocorrelation ( $\left.\alpha_{A R S, A R S}^{\prime}=(0.82,0.88)\right)$, with high autocorrelation both in the foraging $\left(\alpha_{\text {Foraging,Foraging }}^{\prime \prime}=(0.95,0.96)\right)$ and resting state $\left(\alpha_{\text {Resting,Resting }}^{\prime \prime}=(0.87,0.89)\right)$ (Figs. 2 and 3). The spatial pattern of traveling and area-restricted search states largely matched previous work in [11, 14], with the majority of area-restricted search events in the Gerlache and Bransfield straits (Fig. 4). Within area-restricted search, the mean percentage of time spent in foraging state $($ mean $=58.2 \%$, sd $=0.23$ ) was greater than the mean

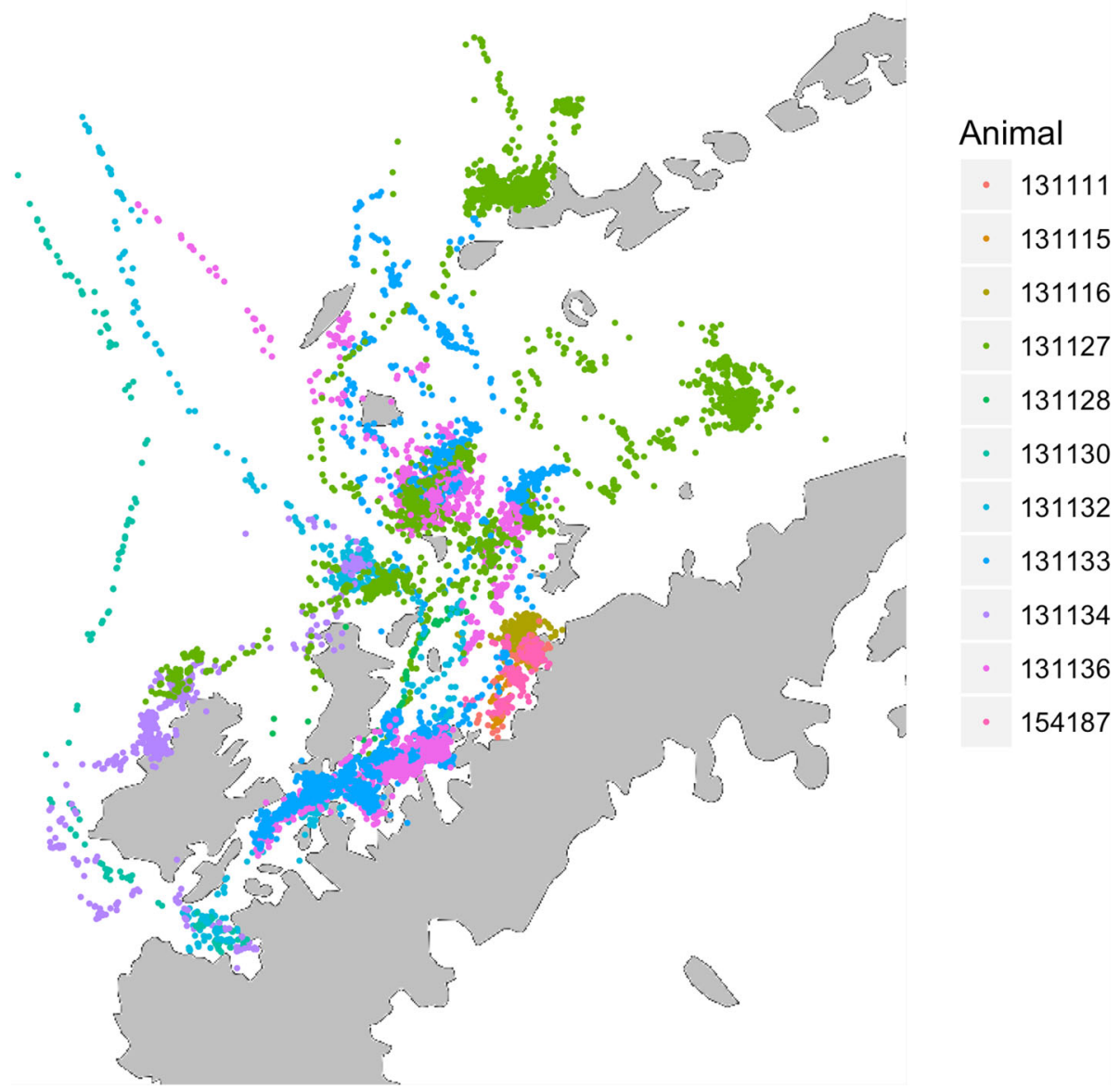

Fig. 1 Filtered geographic observations of 11 adult humpback whales tracked by satellite tag in waters off the West Antarctic Peninsula during Feb-May 2016 


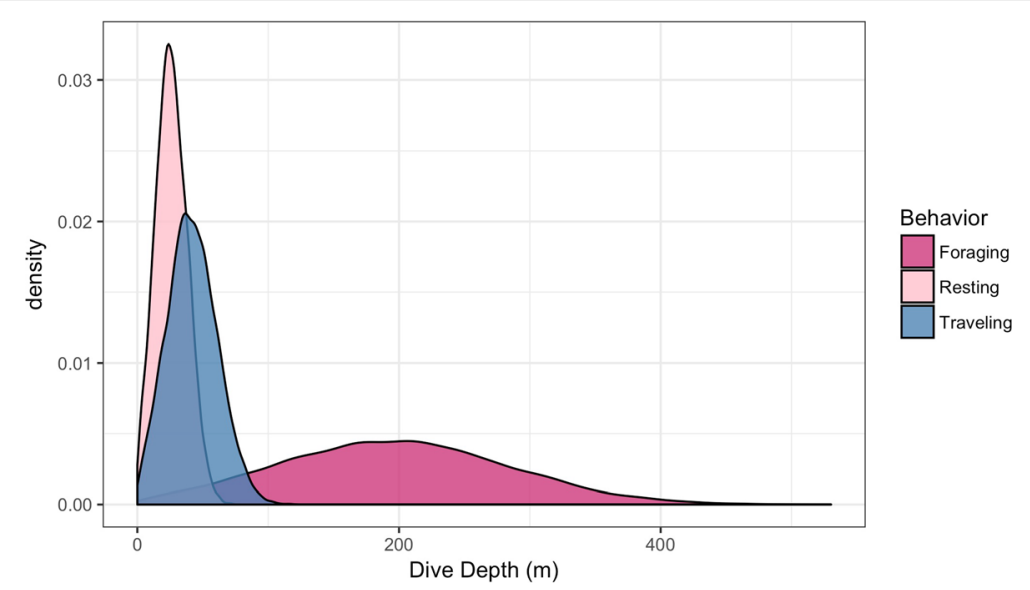

Fig. 2 Predicted dive depth distributions of satellite tagged humpback whales for each of three latent movement behaviors predicted by a nested multivariate movement model

percentage of time spent in the resting state (mean = $22.0 \%$, sd $=0.15$ ). Traveling dives had an estimated mean depth of $41.0 \mathrm{~m}(40.5 \mathrm{~m}, 41.5 \mathrm{~m})$ with the majority of observed dives between $21.5 \mathrm{~m}$ (25th quantile) and $58.5 \mathrm{~m}$ (75th quantile). Foraging dives had an estimated mean depth of $194.3 \mathrm{~m}$ (192.6 m, $195.9 \mathrm{~m})$ with the deepest observed dive of $543.5 \mathrm{~m}$. The majority of observed foraging dives were between $88.5 \mathrm{~m}$ (25th quantile) and $267.5 \mathrm{~m}$ (75th quantile). Resting dives had an estimated mean depth of $25.1 \mathrm{~m}(25.1 \mathrm{~m}, 25.9 \mathrm{~m})$ with the majority of observed dives between $18.5 \mathrm{~m}$ (25th quantile) and $49.0 \mathrm{~m}$ (75th quantile). Resting states occasionally included single deep dives $(\max =395.5 \mathrm{~m})$ followed by a return to typical short dives.

Partitioning the results by time, the model shows a seasonal increase in the foraging state with the mean foraging frequency rising to nearly $70 \%$ in May-June (Fig. 5). While there is not a clear seasonal pattern in dive depths, one noticeable finding is the frequency of late season deep dives in May and June with 616 observed dives greater than $400 \mathrm{~m}$. Given the uneven sampling throughout the year, we avoid overly interpreting this finding, but believe it is worth further investigation. Finally, partitioning dive behavior by time of day showed a decrease in the frequency of foraging state between 10 am-3 pm (Fig. 6).

\section{Discussion}

Using a nested multivariate movement model, we combined two-dimensional movement data with vertical dive data to model foraging behavior in adult humpback whales off the West Antarctic Peninsula. Our foremost goal was to investigate the seasonal increase in area-restricted search state, reported in [14], by explicitly incorporating dive behavior as a more refined signature of whale behavior. By partitioning area-restricted search into foraging and resting states based on an animal's vertical movement, we find a strong seasonal increase in foraging dive behavior in the late austral fall. This observed increase in foraging frequency coincides with changes in krill abundance and distribution in the coastal and continental shelf waters around the Antarctic Peninsula. The life-history of krill in the West Antarctic Peninsula remains poorly understood, but the general pattern is adult krill feeding along the continental shelf in the austral summer, followed by an inshore migration towards icecovered areas during the austral fall [10, 30]. As sea-ice forms, krill aggregate in larger swarms in coastal bays [23, 31]. Humpbacks mirror these changes in distribution, with large aggregations of individuals nearshore and along seasonal ice edges $[9,11,17]$.

The response of whales to the change in krill distribution may represent a strategy to increase fat reserves prior to migration [32]. The greater density of krill may create more efficient foraging opportunities, by reducing the number of dives needed to sustain energetic demands. If foraging is indeed more productive in the late season, this creates a tradeoff between leaving for the calving grounds in order to fulfill reproductive needs, and staying in the Antarctic to increase fat reserves. While the presence of seasonal sea-ice prevents animals from staying year-round, we expect immature or non-reproductively active whales to stay later in the season due to reduced pressure on the timing of northward migration. As the average number of ice free days along the West Antarctic Peninsula rises [33], the ability for whales to remain longer in Antarctic waters may affect the recovery of whales from historic harvest [34], create competition with other krill predators [35], and potential conflict with the growing krill fishery [23, 36, 37].

The strong connection between whale and krill distribution also included daily vertical movements [10]. 


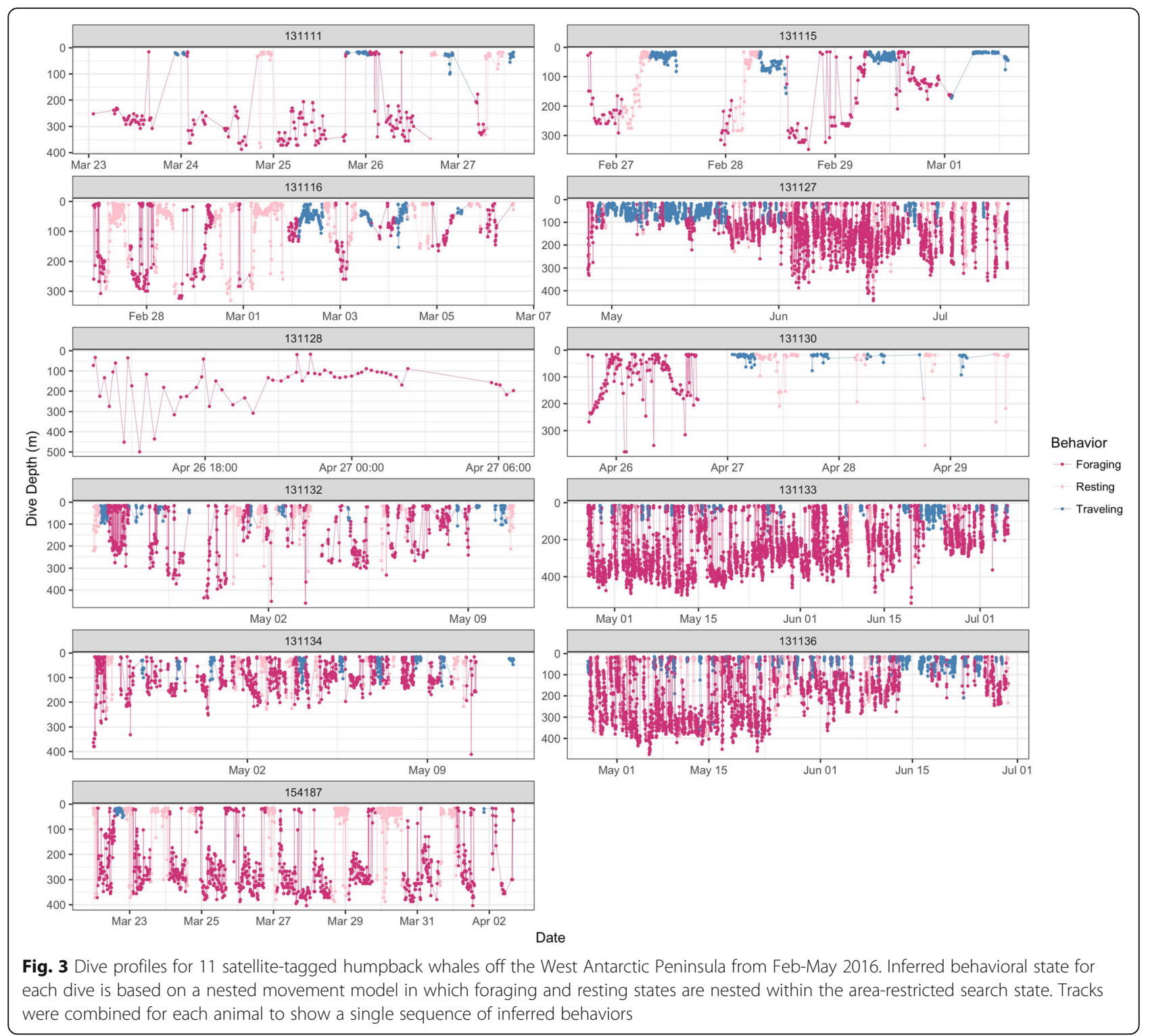

Showed elevated nighttime concentrations of krill near the surface followed by descent to greater than $200 \mathrm{~m}$ during the day in West Antarctic waters. Short-term observations of both whales and krill suggested that whales actively explore the water column to assess the vertical distribution of prey [16]. Our results showed an increase in the frequency of foraging behavior at night. This pattern of behavior also helps explain the presence of isolated deep dives within the resting state, since deep dives are likely exploratory behaviors to assess krill presence in the water column. Deep dives are energetically expensive, and the diel behavior suggest individuals are balancing the cost of dive expenditure and foraging efficiency. Without the temporal context of the resting state, exploratory deep dives may be mistakenly labeled as foraging events. These observations are symptomatic of the larger challenge of matching individual observations with complex latent behavior over discrete time [38].

Detailed examination of our results underscores the need for further development of movement models to represent latent behavior as a combination of local movement and regional context. For example, we observed a potential foraging bout north of Livingston Island that was classified as traveling because individual 131,127 performed a series of short linear movements, with shallow dives to $80-100 \mathrm{~m}$ over a multiple day period. The consistency and tight spatial area of this movement suggests this is likely a foraging event on a shallow krill swarm near the continental shelf. In addition, the location of this event matches an observed krill hotspot reported by [39]. The model may have failed to recognize this foraging bout because it is the 


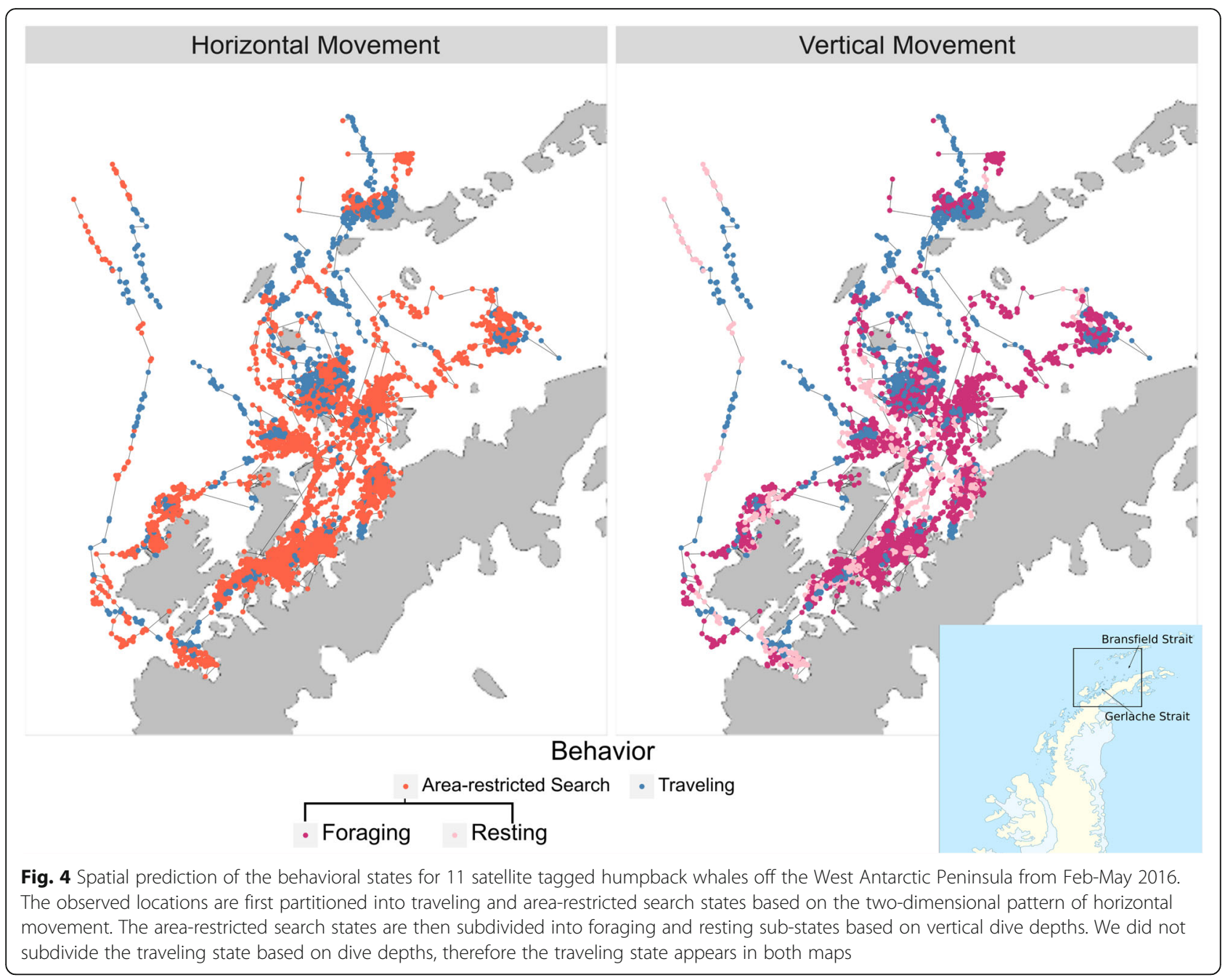

only foraging activity along the continental shelf in our dataset. It is possible that the foraging behavior in this area is distinct from deeper diving events in the Gerlache and Bransfield straits, which make up the majority of our dataset. Similarly, observations of individuals migrating northward across the Drake Passage were likely mislabeled resting based on more erratic movements. Given that the majority of our movement data is within more protected inshore waters, navigating the rougher seas of the open ocean may lead to distinct traveling behaviors. The challenge of collecting movement data across broad spatial scales has limited the development of flexible behavioral models that vary as a function of regional distribution. By combining data across scales, we can better match observed movement patterns with a reasonable number of latent behavioral states, rather than adding additional behavioral states for movement in each new regional context.

A natural extension of the nested behavioral model is the incorporation of environmental covariates for the transitions among states and sub-states [25]. By combining multiple behavioral layers, these approaches could allow ecologists to test the spatial and temporal scale at which environmental covariates become informative. While this holds great promise in moving towards a mechanistic model of animal movement [2], we believe it will be difficult to apply to Antarctic humpbacks foraging on krill. While broad scale predictors such as bathymetry and distance to shore are correlated with humpback presence [17], our exploratory analysis shows relatively little explanatory power on specific behavioral states. Our results, and prior work, show that whale foraging is tightly coupled with krill presence and density $[9,40]$. While there has been significant effort to create environmental models of krill abundance $[13,41]$, a recent review highlighted a lack of predictive power at the local scale [42]. Beyond the tendency of juvenile krill to aggregate near the seasonal ice edges [43], the seasonal and daily vertical movements of krill relate to a complex combination of oceanographic, productivity, and tidal forces [44]. Given the lack of these fine-scale data needed to predict krill aggregations, direct modeling 


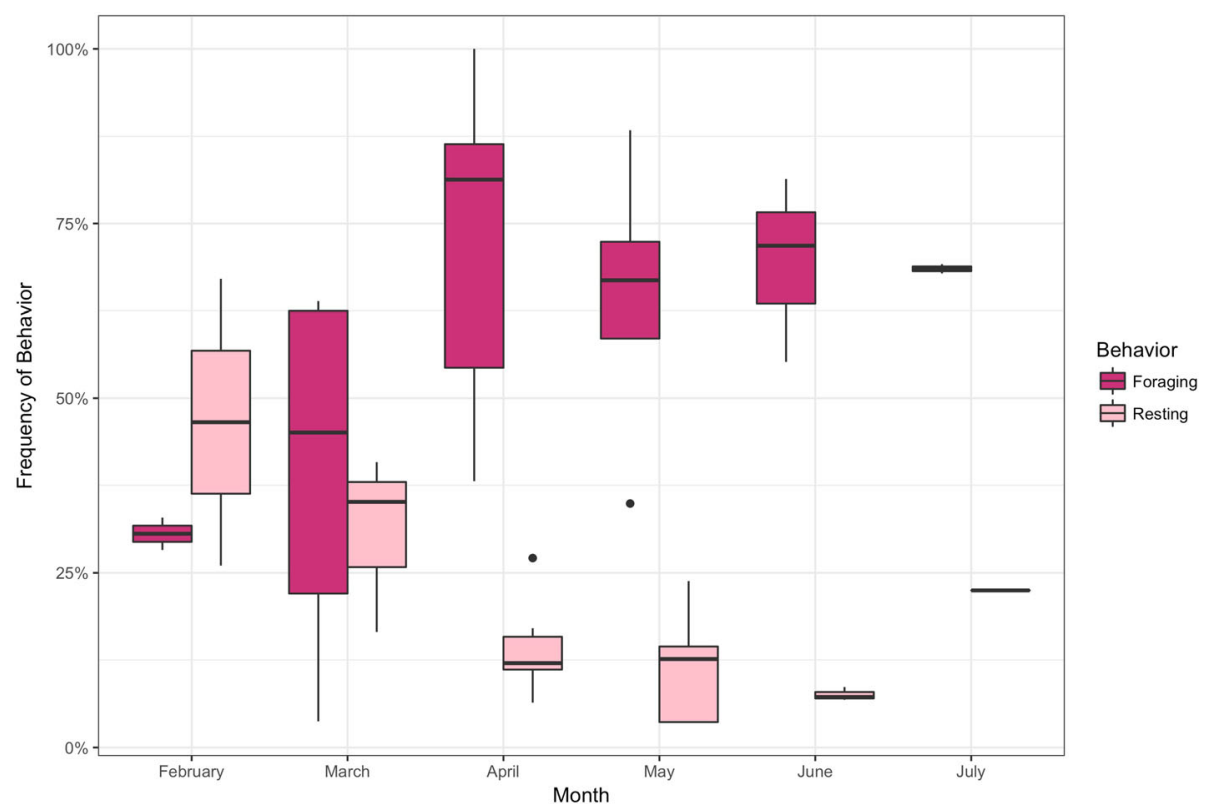

Fig. 5 Seasonal frequency of foraging and resting states for humpback whales satellite tagged off the West Antarctic Peninsula inferred using a nested multivariate movement model. The traveling behavior did not show a consistent seasonal pattern and is not shown below

of krill-predator dive behavior may be a more tractable way of assessing the areas of potential conservation priority in Antarctic waters [13,36].

An intriguing possibility of nested behavioral models is the power to explore the temporal and spatial scale of movement behaviors. By modifying the step duration at each behavioral layer, it will be possible to evaluate the temporal persistence in behaviors, and spatial predictors that best match different temporal scales [38]. For example, at fine scales (100 s of meters), whales are responding to

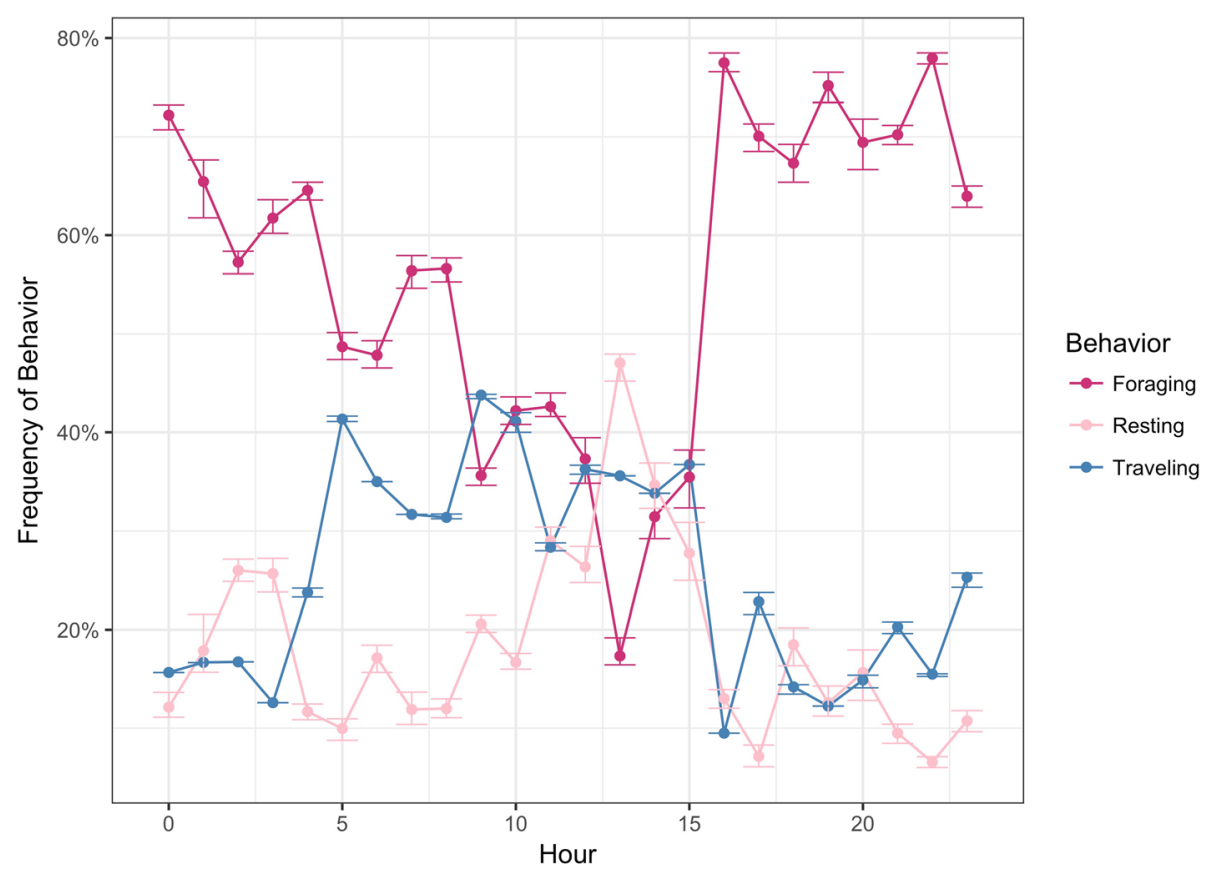

Fig. 6 Daily behavior patterns of satellite tagged humpback whales off the West Antarctic Peninsula inferred using a nested multivariate movement model. The total frequency of behavior across all individuals shows a diurnal drop in foraging behavior during daylight hours. Error bars show the uncertainty in estimates of the behavior states for 50 draws of the posterior distribution for each observation 
changes in resource abundance, whereas at the multiple kilometer scale, humpbacks must avoid encroaching sea-ice to ensure consistent access to the surface to breath. Currently, the framework that describe species occurrence is analytically separate from models that describe movement behaviors. Combining these two fields through nested models, we can begin to ask what are the predictors of animal behavior conditional on species occurrence and broad scale patterns of movement.

\section{Conclusions}

As biologger sensors become more advanced, ecologists are challenged to combine the data collected at different temporal and spatial extents to infer animal behavior. The spatial movements of whales are captured at a lower temporal frequency than the dive movements, but both encode information on foraging behavior. Our combined model can more realistically model foraging behavior by explicitly including vertical movement as a predictor of a nested latent state. Our results show a strong increase in foraging frequency in the late austral fall, coinciding with published patterns of krill movement. Given the rapid environmental change in the region, our study will help outline the physiological demands and the potential changes in whale distribution during global change in polar waters.

\section{Additional file}

Additional file 1: Table S1. Parameter estimates for the humpback foraging, traveling, and resting behavioral states inferred from the nested multivariate movement model. (DOCX $19 \mathrm{~kb}$ )

\section{Abbreviations}

ARS: Area-restricted search

\section{Acknowledgements}

We are grateful to the Australian Antarctic Division for their support of this research, with special thanks to the NSF LTER, Nick Gales, Mike Double, Elanor Bell, and Virginia Andrews-Goff.

\section{Funding}

Research was supported by Antarctic Wildlife Research Fund (ANT-0823101), NSF OPP National Science Foundation ANT- 0823101, 1250208, and 1440435, International Whaling Commission, and the Southern Ocean Research Partnership.

\section{Availability of data and materials}

Source code and data visualizations are available on github (https://bw4sz.github.io/ WhalePhys/)

\section{Authors' contributions}

ASF and LI collected and organized the data. ASF and BGW conceived the analysis. BGW performed the analysis and wrote the text. All authors commented on text and figures. All authors read and approved the final manuscript.

\section{Ethics approval and consent to participate}

All animals were handled by experienced professionals under permits: NMFS 14907, 14,809, and 14,856, ACA Permits 2009-013 and 2015-011, Duke University IACUC A049-122-02 and OSU ACUP 4513.
Consent for publication

Not applicable.

\section{Competing interests}

The authors declare no conflicts of information.

\section{Publisher's Note}

Springer Nature remains neutral with regard to jurisdictional claims in published maps and institutional affiliations.

\section{Author details}

${ }^{1}$ Department of Fisheries and Wildlife, Marine Mammal Institute, Oregon State University, 2030 Marine Science Drive, Newport, OR 97365, USA.

${ }^{2}$ Institute of Marine Sciences, Department of Ecology and Evolutionary Biology, UC Santa Cruz, 115 McAllister Way, Santa Cruz, CA 95060, USA.

Received: 14 May 2018 Accepted: 16 July 2018

Published online: 20 September 2018

\section{References}

1. Hays GC, Ferreira LC, Sequeira AMM, Meekan MG, Duarte CM, Bailey H, et al. Key questions in marine megafauna movement ecology. Trends Ecol Evol. 2016:31:463-75.

2. Gurarie E, Bracis C, Delgado M, Meckley TD, Kojola I, Wagner CM. What is the animal doing? Tools for exploring behavioural structure in animal movements. J Anim Ecol. 2016;85(1):69-84.

3. Buderman FE, Hooten MB, Ivan JS, Shenk TM. A functional model for characterizing long-distance movement behaviour. Methods Ecol Evol. 2016; 7:264-73.

4. McClintock BT, Russell DJF, Matthiopoulos J, King R. Combining individual animal movement and ancillary biotelemetry data to investigate population-level activity budgets. Ecology. 2013:94:838-49.

5. Bestley S, Jonsen ID, Hindell MA, Harcourt RG, Gales NJ. Taking animal tracking to new depths: synthesizing horizontal - vertical movement relationships for four marine predators. Ecology. 2015;96:417-27.

6. Leos-Barajas V, Gangloff EJ, Adam T, Langrock R, van Beest FM, Nabe-Nielsen $J$, et al. Multi-scale modeling of animal movement and general behavior data using hidden Markov models with hierarchical structures. J Agric Biol Environ Stat. 2017;22:232-48

7. Leos-Barajas V, Photopoulou T, Langrock R, Patterson TA, Watanabe YY, Murgatroyd M, Papastamatiou YP, O'Hara RB. Analysis of animal accelerometer data using hidden Markov models. Methods Ecol. Evol. 2017;8(2):161-173.

8. Börger L. EDITORIAL: Stuck in motion? Reconnecting questions and tools in movement ecology. J. Anim. Ecol. 2016;85(1):5-10.

9. Nowacek DP, Friedlaender AS, Halpin PN, Hazen EL, Johnston DW, Read AJ, et al. Super-Aggregations of Krill and Humpback Whales in Wilhelmina Bay, Antarctic Peninsula. PLoS One. 2011:6:2-6.

10. Cleary A, Durbin E, Casas M, Zhou M. Winter distribution and size structure of Antarctic krill Euphausia superba populations in-shore along the West Antarctic peninsula. Mar Ecol Prog Ser. 2016;552:115-29.

11. Weinstein BG, Double M, Gales N, Johnston DW, Friedlaender AS. Identifying overlap between humpback whale foraging grounds and the Antarctic krill fishery. Biol Conserv. 2017;210:184-91.

12. Johnston DW, Friedlaender AS, Read AJ, Nowacek DP. Initial density estimates of humpback whales Megaptera novaeangliae in the inshore waters of the western Antarctic Peninsula during the late autumn. Endanger Species Res. 2012;18:63-71

13. Herr H, Viquerat S, Siegel V, Gutt J. Horizontal niche partitioning of humpback and fin whales around the West Antarctic Peninsula: evidence from a concurrent whale and krill survey. Polar Biol. 2016;39(5):799-818.

14. Weinstein BG, Friedlaender AS. Dynamic foraging of a top predator in a seasonal polar marine environment. Oecologia. 2017;185:427-35.

15. Tyson RB, Friedlaender AS, Nowacek DP. Does optimal foraging theory predict the foraging performance of a large air-breathing marine predator? Anim Behav. 2016:116:223-35.

16. Friedlaender AS, Tyson RB, Stimpert AK, Read AJ, Nowacek DP. Extreme diel variation in the feeding behavior of humpback whales along the western Antarctic Peninsula during autumn. Mar Ecol Prog Ser. 2013;494:281-9.

17. Friedlaender AS, Johnston DW, Fraser WR, Burns J, Patrick NH, Costa DP. Ecological niche modeling of sympatric krill predators around Marguerite 
Bay, western Antarctic peninsula. Deep-Sea Res II Top Stud Oceanogr. 2011; 58:1729-40.

18. Goldbogen JA, Friedlaender AS, Calambokidis J, McKenna MF, Simon M. Integrative approaches to the study of baleen whale diving behavior, feeding performance, and foraging ecology. Bioscience. 2013;63:90-100.

19. Thiele D, Chester ET, Moore SE, Ana S, Hildebrand JA, Friedlaender AS. Seasonal variability in whale encounters in the Western Antarctic Peninsula. Deep-Sea Res II Top Stud Oceanogr. 2004;51:2311-25.

20. Matsuoka K, Hakamada T, Kiwada H, Murase H, Nishiwaki S. Distributions and standardized abundance estimates for humpback, fin and blue whales in the Antarctic areas IIIE, IV, V and VIW $\left(35^{\circ} \mathrm{E}-145^{\circ} \mathrm{W}\right)$, south of $60^{\circ} \mathrm{S}$. Rep Int Whal Comm. 2006;SC/D06/J7:1-37

21. Meredith MP, Stammerjohn SE, Venables HJ, Ducklow HW, Martinson DG, lannuzzi RA, et al. Changing distributions of sea ice melt and meteoric water west of the Antarctic Peninsula. Deep Sea Res Part II Top Stud Oceanogr. 2017;139:40-57.

22. de la Mare WK. Abrupt mid-twentieth-century decline in Antarctic Sea-ice extent from whaling records. Nature. 1997;389:57-60.

23. Nicol S, Worby A, Leaper R. Changes in the Antarctic Sea ice ecosystem: potential effects on krill and baleen whales. Mar Freshw Res. 2008;59:361-82.

24. Jonsen ID, Flemming J, Myers R. Robust state-space modeling of animal movement data. Ecology. 2005;86:2874-80.

25. Bestley S, Jonsen ID, Hindell MA, Guinet C, Charrassin JB. Integrative modelling of animal movement: incorporating in situ habitat and behavioural information for a migratory marine predator. Proc R Soc B Biol Sci. 2013;280:2012-262.

26. Dolphin WF. Foraging dive patterns of humpback whales, Megaptera novaeangliae, in Southeast Alaska: a cost-benefit analysis. Can J Zool. 1988;66:2432-41.

27. Ware C, Friedlaender AS, Nowacek DP. Shallow and deep lunge feeding of humpback whales in fjords of the West Antarctic peninsula. Mar Mammal Sci. 2011:27:587-605.

28. Plummer M. JAGS: a program for analysis of Bayesian graphical models using Gibbs sampling. Proc 3rd Int Work Distrib Stat Comput. 2003;124:1-10.

29. Gelman A, Hill J. Data analysis using regression and multilevel/hierarchical models. Cambridge: Cambridge University Press; 2007.

30. Nicol S. Krill, currents, and sea ice: Euphausia superba and its changing environment. Bioscience. 2006;56:111.

31. Brierley AS, Fernandes PG, Brandon MA, Armstrong F, Millard NW, Mcphail SD, et al. Antarctic krill under sea ice: elevated abundance in a narrow band just south of ice edge. Source Sci New Ser. 2002;295:1890-2.

32. Bengtson Nash SM, Castrillon J, Eisenmann P, Fry B, Shuker JD, Cropp RA, et al. Signals from the south; humpback whales carry messages of Antarctic Sea-ice ecosystem variability. Glob Chang Biol. 2018;24(4): 1500-10.

33. Hobbs WR, Massom R, Stammerjohn S, Reid P, Williams G, Meier W. A review of recent changes in Southern Ocean sea ice, their drivers and forcings. Glob Planet Change. 2016;143:228-50.

34. Obryk MK, Doran PT, Friedlaender AS, Gooseff MN, Li W, Morgan-Kiss RM, et al. Responses of Antarctic marine and freshwater ecosystems to changing ice conditions. Bioscience. 2016;66:864-79.

35. Siegel V, Watkins JL. Distribution, biomass, and demography of Antarctic krill. In: Siegel V, editor. Biol Ecol Antarct krill. Cham: Springer International Publishing; 2016. p. 321-50. Available from: http://link.springer.com/10.1007/ 978-3-319-29279-3.

36. Santora JA, Reiss CS, Loeb VJ, Veit RR. Spatial association between hotspots of baleen whales and demographic patterns of Antarctic krill Euphausia superba suggests size-dependent predation. Mar Ecol Prog Ser. 2010;405:255-69.

37. Cavanagh RD, Hill SL, Knowland CA, Grant SM. Stakeholder perspectives on ecosystem-based management of the Antarctic krill fishery. Mar Policy. 2016;68:205-11.

38. McClintock BT, Johnson DS, Hooten MB, Ver Hoef JM, Morales JM. When to be discrete: the importance of time formulation in understanding animal movement. Mov Ecol. 2014;2:21.

39. Reiss CS, Cossio A, Santora JA, Dietrich KS, Murray A, Greg Mitchell B, et al. Overwinter habitat selection by Antarctic krill under varying sea-ice conditions: implications for top predators and fishery management. Mar Ecol Prog Ser. 2017;568:1-16.

40. Friedlaender AS, Halpin PN, Qian SS, Lawson GL, Wiebe PH, Thiele D, et al. Whale distribution in relation to prey abundance and oceanographic processes in shelf waters of the Western Antarctic Peninsula. Mar Ecol Prog Ser. 2006;317:297-310.

41. Tarling GA, Klevjer T, Fielding S, Watkins J, Atkinson A, Murphy E, et al. Variability and predictability of Antarctic krill swarm structure. Deep-Sea Res I Oceanogr Res Pap. 2009;56:1994-2012.

42. Trathan PN, Hill SL. In: Siegel V, editor. Biology and Ecology of Antarctic Krill. Cham: Springer International Publishing; 2016.

43. Brierley AS. Antarctic krill under sea ice: elevated abundance in a narrow band just south of ice edge. Science. 2002;295:1890-2.

44. Bernard KS, Cimino M, Fraser W, Kohut J, Oliver MJ, Patterson-Fraser D, et al. Factors that affect the nearshore aggregations of Antarctic krill in a biological hotspot. Deep-Sea Res I Oceanogr Res Pap. 2017;126:139-47.
Ready to submit your research? Choose BMC and benefit from:

- fast, convenient online submission

- thorough peer review by experienced researchers in your field

- rapid publication on acceptance

- support for research data, including large and complex data types

- gold Open Access which fosters wider collaboration and increased citations

- maximum visibility for your research: over $100 \mathrm{M}$ website views per year

At BMC, research is always in progress.

Learn more biomedcentral.com/submissions 